
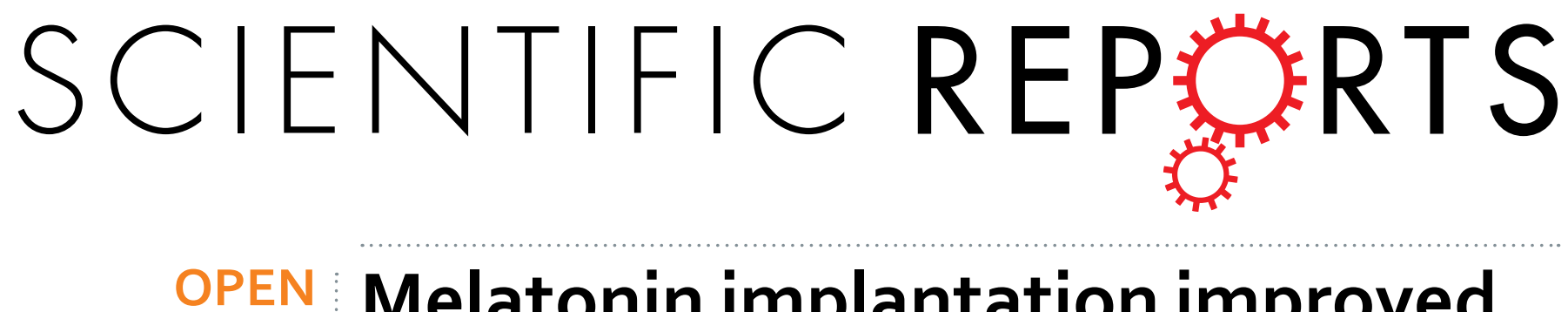

\title{
Melatonin implantation improved the egg-laying rate and quality in hens past their peak egg-laying age
}

Received: 29 July 2016

Accepted: 29 November 2016

Published: 23 December 2016
Yaxiong Jia ${ }^{2, *}$, Minghui Yang ${ }^{1, *}$, Kuanfeng Zhu ${ }^{1, *}$, Liang Wang ${ }^{2}$, Yukun Song ${ }^{1}$, Jing Wang ${ }^{1}$, Wenxiang Qin ${ }^{1}$, Zhiyuan Xu ${ }^{1,3}$, Yu Chen ${ }^{2}$ \& Guoshi Liu ${ }^{1}$

The egg-laying rates of hens approximately 470 days of age exhibited a positive correlation to blood melatonin levels. The hens with an egg-laying rate $<30 \%, 30 \sim 90 \%$ and $\geq 90 \%$ had blood melatonin levels of $5.8 \pm 2.6,74.0 \pm 32.9$ and $445.9 \pm 115.3 \mathrm{ng} / \mathrm{ml}$, respectively. When $10 \mathrm{mg}$ of melatonin was implanted into the hens at 300, 360, 470 and 550 days of age, the egg-laying rates increased $4.63 \pm 0.46 \%, 8.38 \pm 1.45 \%, 4.93 \pm 0.85 \%$ and $7.93 \pm 0.91 \%$, respectively, compared to that of the controls. Melatonin implantation in hens at 300-470 days of age was observed to enhance egg production and reduce the rate of appearance of sharpei eggs. Melatonin $(10 \mathrm{mg})$ implanted in hens 360 days of age did not influence the blood levels of progesterone (P4) or the gene expression levels of ovarian follicle stimulating hormone receptor (FSHR), luteinizing hormone receptor (LHR), oestradiol receptor alpha $(E R \alpha)$, superoxide dismutase 2 (SOD2) or melatonin receptor 1 (MT1). In contrast, melatonin significantly elevated the serum oestradiol-17 $\beta$ (E2) content, down-regulated the gene expression of gonadotropin-inhibitory hormone receptor (GnIHR), and enhanced the expression of melatonin receptor 2 (MT2). This result indicates that the improved egg-laying rate by melatonin was the result of increased serum oestradiol and decreased ovarian GnIHR. These alterations may be mediated by $M T 2$ activation.

Several studies have reported that melatonin is capable of regulating the reproductive activities of birds. For example, in jungle bush quail (Perdicula asiatica), the activity of their pineal glands exhibited an inversed relationship with their ovarian performance ${ }^{1}$. Melatonin administration for 30 days completely suppressed the seasonal gonadal growth in male Indian finches (Estrilda amandava) ${ }^{2}$. For the white leghorn roosters, melatonin treatment suppressed their LH secretion in a dose- and time-related manner ${ }^{3}$. Melatonin could also up-regulate the expression of gonadotropin-inhibitory hormone in the avian brain and thus suppressed pituitary gonadotropin secretion ${ }^{4}$.

Many recent studies, however, reported beneficial effects of melatonin on animal reproduction. Melatonin application promoted the maturation and development of oocytes as well as early embryos in mammals including the mouse $\mathrm{s}^{5}$, human ${ }^{6}$, porcine $\mathrm{e}^{7}$, bovine ${ }^{8}$ and sheep ${ }^{9}$. In addition to mammals, melatonin has also been shown to have beneficial effects on birds. For example, a melatonin supplement could improve the feeding efficiency of chickens and promote their growth ${ }^{10,11}$. In birds, melatonin also functions as an immunoenhancement agent ${ }^{12}$. Its supplementation elevated cellular and humoral immune responses in Japanese quail ${ }^{13}$ and chicken ${ }^{14-16}$. The signalling pathway analysis showed that both cellular and humoral immunoresponses triggered by melatonin were exclusively mediated by its receptor subtype MT2 (Mel 1b) ${ }^{17}$.

Egg production is a complex process that not only involves the reproductive system but also depends on the availability of specific nutrients and the efficiency of their utilization. For example, melatonin, as a nutrient, may enhance the egg laying productivity of hens. The egg-laying peak is a period when the egg-laying rate is higher than $90 \%$ in hens and often appears in hens before the age of 300 days ${ }^{18,19}$. After that period, their egg-laying productivity declines with age ${ }^{20}$. Previous melatonin research has focused on the period around the egg-laying

${ }^{1}$ National Engineering Laboratory for Animal Breeding, Key Laboratory of Animal Genetics and Breeding of the Ministry of Agriculture, Beijing Key Laboratory for Animal Genetic Improvement, College of Animal Science and Technology, China Agricultural University, Beijing, China. ${ }^{2}$ Beijing Animal Husbandry Station, Beijing, China. ${ }^{3}$ College of Animal Science and Technology, Jilin Agricultural University, Changchun, Jilin, China. ${ }^{*}$ These authors contributed equally to this work. Correspondence and requests for materials should be addressed to G.L. (email: gshliu@cau. edu.cn) 


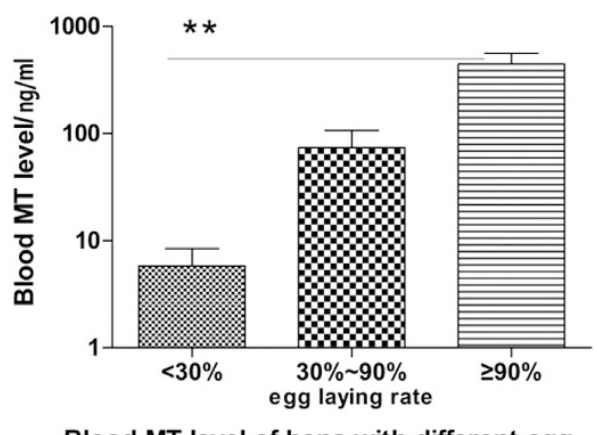

Blood MT level of hens with different egg laying rate

Figure 1. The association of blood melatonin levels and egg-laying rates in hens (440-470 days old). Egg laying numbers were recorded daily for a month before melatonin implantation. The blood was collected from the different groups classified by the egg-laying rates $(n=12)$. Data were expressed as the means \pm SEM. “**” represents extremely significant $(\mathrm{p}<0.01)$.

(a)

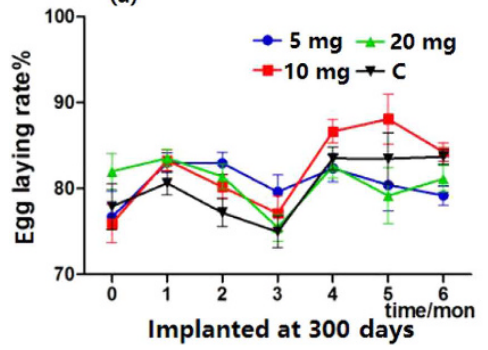

(d)

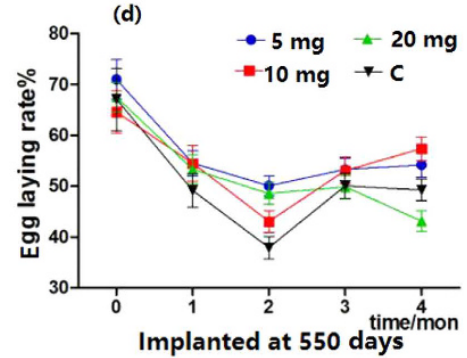

(b)

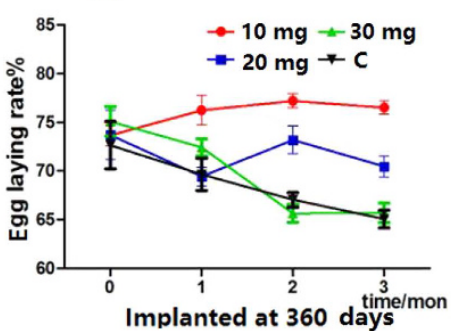

(e) (c)
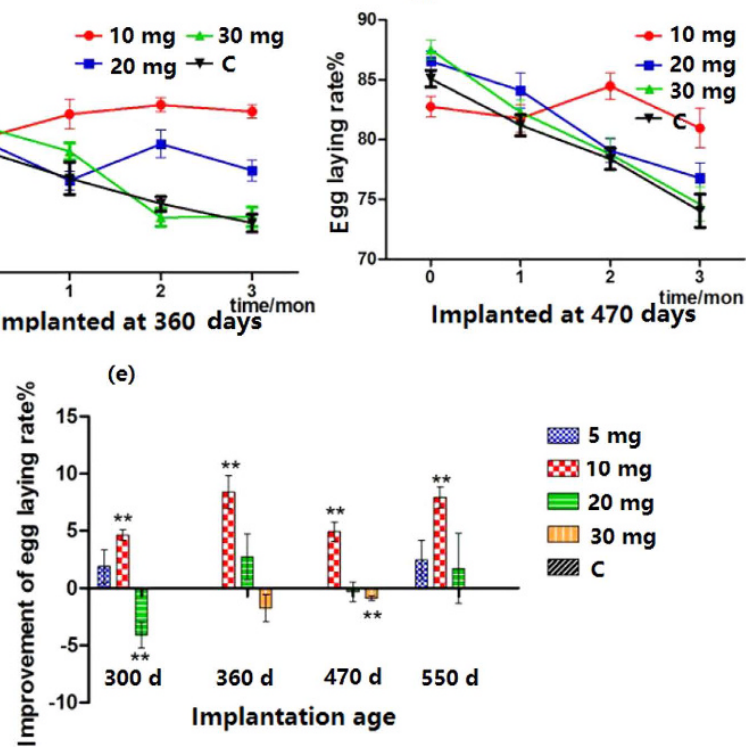

$5 \mathrm{mg}$

\$ $10 \mathrm{mg}$

$\equiv 20 \mathrm{mg}$

미 $30 \mathrm{mg}$

UIIA C

Figure 2. Effect of melatonin implantation on egg-laying rate. (a-d) Show the egg-laying rate of hens at different ages after melatonin implantation. (e) Shows the summary of the effects of melatonin implantation on the egg-laying rate in hens at different ages. “**” represents extremely significant $(\mathrm{p}<0.01)$.

peak or earlier in chickens $s^{3,11,16,21,22}$. There is no report related to the effects of melatonin on hens that are past their egg-laying peak. In the current study, the effects of melatonin on the egg production of these hens will be investigated.

\section{Results}

Higher blood melatonin levels in hens 470 days of age were associated with more egg production. The results are listed in Fig. 1. It was shown that hens 470 days of age with an egg-laying rate more than $90 \%$ had significantly higher melatonin levels than those with an egg-laying rate below $30 \%$ (445.9 \pm 115.3 vs $5.8 \pm 2.6 \mathrm{ng} / \mathrm{ml}$, respectively).

Effect of melatonin implantation on the egg-laying rate. When melatonin (10 $\mathrm{mg})$ was implanted into hens 360 days of age, their egg-laying rates significantly increased compared to those of their untreated counterparts, and this increase lasted for at least 6 months; however, the effects of implantation of $5 \mathrm{mg}$ of melatonin lasted only 3 months (Fig. 2a). Similar effects were observed in the hens 470 and 550 days old (Fig. 2b-d). The results of melatonin $(10 \mathrm{mg})$ treatment were more significant in the hens 550 days old. Throughout the experimental period, the egg-laying rate of old hens with melatonin implantation was significantly higher than those of their untreated counterparts (Fig. 2d). The most effective dose of melatonin implantation was $10 \mathrm{mg} / \mathrm{hen}$, and at this dose, the average egg-laying rate in hens of different ages (from 300-550 days) was uniformly increased at a range of $4.63-8.38 \%$ (Fig. 2e). High melatonin levels, for example $20 \mathrm{mg} / \mathrm{hen}$, resulted in a slightly inhibitory effect on the egg-laying rate. 

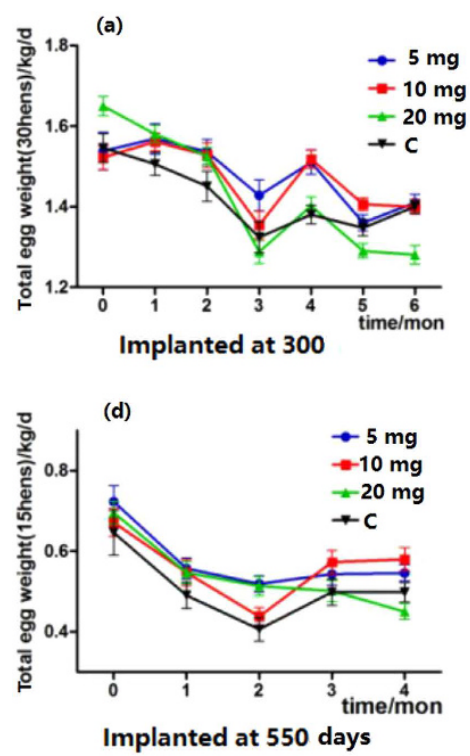

(b)
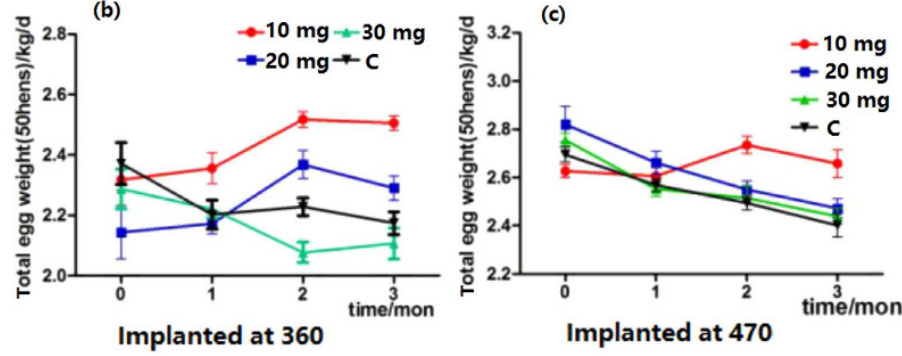

(e)

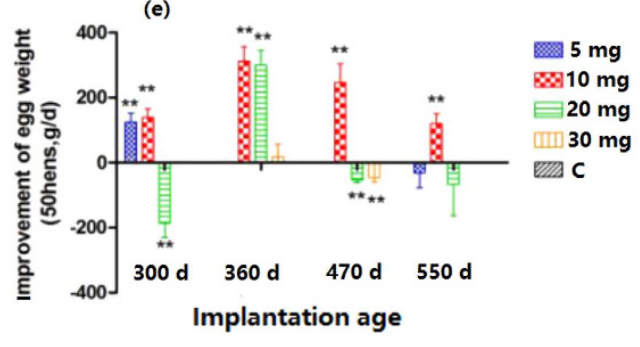

Figure 3. Effect of melatonin implantation on total egg weight. (a-d) Shows the total weight of eggs laid by hens at different ages after melatonin implantation. (e) Shows the summary of the effects of melatonin implantation on total egg weight (calculated daily). "**” represents significant differences of $p<0.01$.

Effects of melatonin implantation on total egg weight. The effects of melatonin on total egg weight were variable depending on the dosages of melatonin used and the age of the hens. The results are listed in Fig. 3. In hens 300 days of age with either 5 or $10 \mathrm{mg}$ of implanted melatonin, the total egg weights were significantly increased compared to the controls after 4 months of treatment (Fig. 3a). In hens 360 days of age, $20 \mathrm{mg}$ of implanted melatonin increased the total egg weight compared to the controls, but $30 \mathrm{mg}$ had the opposite effect (Fig. 3b). The best results were obtained from the hens 470 days of age with $10 \mathrm{mg}$ of implanted melatonin. In this group, the total egg weights were significantly increased on the second month after melatonin application and maintained the highest level among all groups until the end of the study (Fig. 3c). In hens 550 days of age, different doses of implanted melatonin collectively increased their total egg weights at different time points; otherwise, the egg weights were similar to that of the control group (Fig. 3d).

Generally, melatonin implantation at a dosage of $10 \mathrm{mg}$ in the hens 300-470 days old increased their egg weight 3-6g/hen/day compared to that of their untreated counterparts. This increase lasted at least 3 months and was statistically significant $(\mathrm{p}<0.01)$. However, a high dose of melatonin, for example $20 \mathrm{mg}$, had the opposite effect (Fig. 3e).

Effects of melatonin implantation on the rates of broken and sharpei eggs. Melatonin implantation had no significant effect on the broken egg rate among the different age groups. The egg sharpei rate in hens 360 days of age implanted with $10 \mathrm{mg}$ of melatonin was slightly lower than that in the control group. However, the egg sharpei rate in hens 470 days of age implanted with $10 \mathrm{mg}$ of melatonin was significantly lower than that of the control $(3.3 \pm 0.36 \%$ vs $5.0 \pm 0.47 \%)(\mathrm{p}<0.05)$ (Fig. $4 \mathrm{a})$.

Effects of melatonin implantation on blood E2 and P4 levels. Melatonin implantation at a dose of $10 \mathrm{mg}$ significantly increased the blood level of E2 in hens 360 days of age compared to that in the controls $(900.1 \pm 34.4 \mathrm{vs} 780.0 \pm 44.6 \mathrm{pg} / \mathrm{ml})(\mathrm{p}<0.05)$ (Table 1$)$ and had no significant influence on other groups. Melatonin application did not impact the blood $\mathrm{P} 4$ levels in any groups.

Effect of melatonin implantation on ovarian gene expression. After 3 months of melatonin implantation $(10 \mathrm{mg}$ ), the expression of MT2 mRNA in small white follicles of hens 360 days old was up-regulated; however, GnIHR expression was down-regulated. Melatonin application had no significant influence on the gene expression levels of MT1, SOD2, ER $\alpha$, FSHR and LHR (Fig. 5).

\section{Discussion}

There are few reports that are related to the effects of melatonin application on the yield of egg production in hens, especially in hens that are past the duration of their peak egg-laying rate, such as in the hens 470 to 550 days old. In the current study, it was found that in hens of 470 days of age, the egg-laying rate was positively associated with blood melatonin levels. Furthermore, melatonin implantation at a dose of $10 \mathrm{mg}$ significantly improved their egg-laying rate. This phenomenon was also observed in different age groups from 300-550 days old when the suitable melatonin dose $(10 \mathrm{mg})$ was used. A relatively high dose of implanted melatonin $(30 \mathrm{mg})$ had a negative effect on the egg-laying rate. In addition to the increase in the egg-laying rate, melatonin (10 $\mathrm{mg})$ implantation also improved the quality of the eggs, as indicated by the reduced sharpei egg rate. 

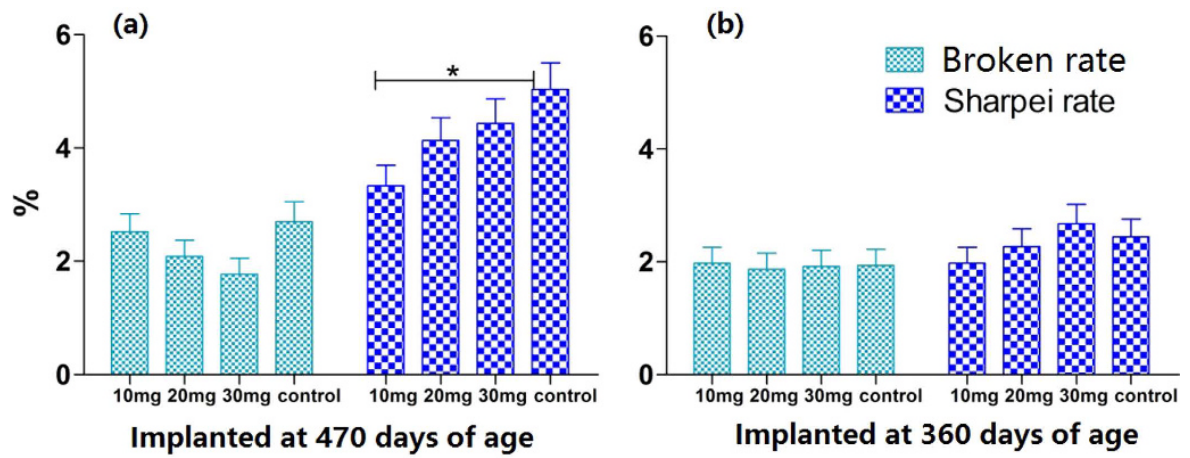

Figure 4. Effect of melatonin implantation on egg quality. (a) Shows the effect of melatonin implanted for 3 months at 470 days of age on egg broken rate and Sharpei rate. (b) Shows the effect of melatonin implanted for 3 months at 360 days of age on egg broken rate and Sharpei rate. Data were expressed as the mean (after 3 months of melatonin treatment $) \pm$ SEM. “`” represents significant differences $(\mathrm{p}<0.05)$.

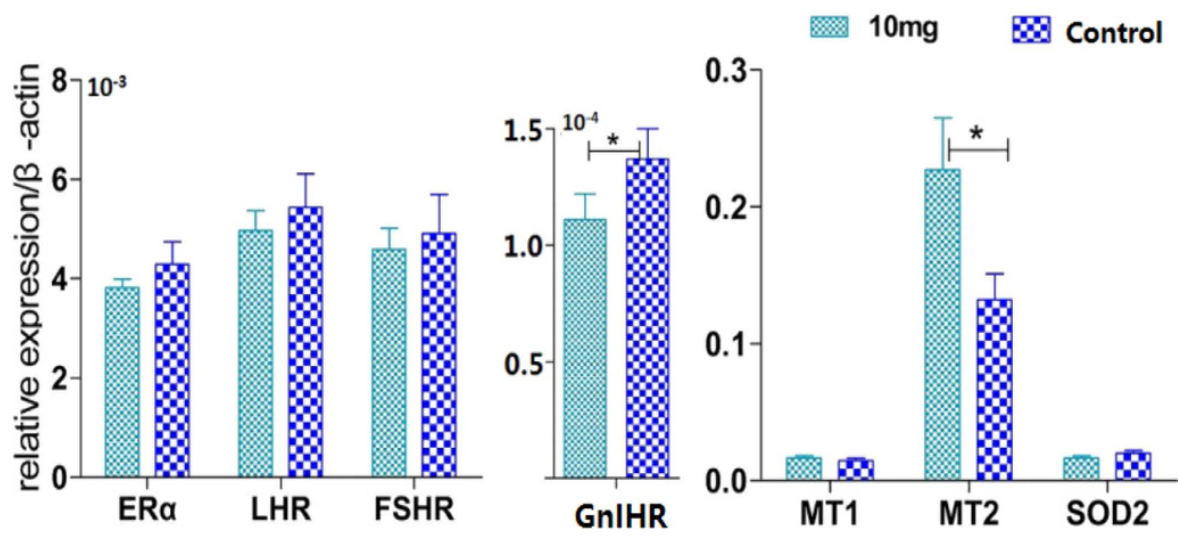

Figure 5. Effect of melatonin implantation on ovary gene expression. The small white follicles were used to analyse the expression of genes that are related to the effects of melatonin on egg laying. The samples were collected 3 months after melatonin implantation in hens 360 days old. Data were expressed as the mean \pm SEM. “*” represents significant differences $(\mathrm{p}<0.05)$.

\begin{tabular}{|c|c|c|c|c|}
\hline & Implantation age & Time/month & $10 \mathrm{mg}$ & control \\
\hline \multirow{4}{*}{$\mathrm{E} 2(\mathrm{pg} / \mathrm{ml})$} & \multirow{2}{*}{$360 \mathrm{~d}$} & 0 & - & - \\
\hline & & 3 & $900.1 \pm 34.4^{\mathrm{a}}$ & $780.0 \pm 44.6^{\mathrm{b}}$ \\
\hline & \multirow{2}{*}{$470 \mathrm{~d}$} & 0 & - & - \\
\hline & & 3 & $823.3 \pm 80.4$ & $828.0 \pm 83.2$ \\
\hline \multirow{4}{*}{$\mathrm{P} 4(\mathrm{pg} / \mathrm{ml})$} & \multirow{2}{*}{$360 \mathrm{~d}$} & 0 & - & - \\
\hline & & 3 & $116.3 \pm 18.1$ & $92.7 \pm 10.5$ \\
\hline & \multirow{2}{*}{$470 \mathrm{~d}$} & 0 & $115.3 \pm 10.5$ & $233.9 \pm 80.3$ \\
\hline & & 3 & $72.1 \pm 8.2$ & $97.0 \pm 15.2$ \\
\hline
\end{tabular}

Table 1. Effect of melatonin implantation on blood E2 and P4 levels. In the same line, different small letters mean significance of $\mathrm{p}<0.05$. Data were expressed as the means $\pm \mathrm{SEM}$.

Many studies have shown that melatonin plays an important role in animal reproduction. Melatonin could enhance the maturation of oocytes and the development of follicles in mammals ${ }^{23-27}$ and fish ${ }^{28,29}$. Despite the great differences between birds and mammals, melatonin may play a similar role in the maturation of oocytes and the development of follicles in birds as it does in mammals. Melatonin and its receptors were found to be present in the ovary. MT1 and MT2 were expressed in both the thecal and granulosa layers ${ }^{30}$. It was reported that MT1 and MT3 were negatively correlated with the total number of eggs yielded in hens 300 days of age that were exposed to different monochromatic light ${ }^{31}$. We observed that melatonin implantation did not influence the expression of ovarian MT1 but up-regulated the expression of MT2. Interestingly, similar to MT2, GnIHR was also found to be expressed in both the thecal and granulosa layers ${ }^{32}$. It has been reported that E2 secretion 
and $G n I H R$ expression regulate egg production and quality ${ }^{33-36}$. GnIHR is mainly expressed in the pituitary. It participates in the negative control of luteinizing hormone $(\mathrm{LH})$ and follicle stimulating hormone $(\mathrm{FSH})^{21}$. $G n I H R$ was also found in the chicken ovary and is expressed in every stage of the follicle. Expression of $G n I H R$ declines throughout sex maturation ${ }^{32}$. In the current study, melatonin was found to down-regulate expression of GnIHR in the ovary. This result indicated that melatonin-promoted ovulation in hens might be through the GnIHR-LH-FSH pathway.

Even though a positive correlation between GnIHR and MT2 expression in the testes of European starlings has been reported ${ }^{22}$, the concrete mechanism for this correlation is still not clear. Furthermore, their relationship in the ovary is virtually unknown. Granulosa cells are essential for oocyte maturation and ovarian ovulation. Glucose metabolism in mouse cumulus cells could prevent oocyte ageing ${ }^{37}$. Coculture with cumulus-derived cells in vitro promotes porcine and sheep oocyte maturation ${ }^{38}$. Melatonin and its receptor MT1 have been reported to be involved in the downstream reaction to luteinizing hormone and to participate in the regulation of luteinization in the mouse ${ }^{39}$. In the current study, it seems that the down-regulation of GnIHR expression by melatonin might be mediated by MT2 in the granulosa layers and then promote ovulation.

Reactive oxygen species (ROS) caused by ageing and environmental stress will significantly affect an animal's reproduction, suppressing the reproductive potential. The ROS caused by reproductive ageing is associated with changes in oocyte mitochondrial dynamics and function and mtDNA quantity and prevents oocyte maturation ${ }^{40}$. It has been reported that heat shock results in an inhibitory effect on porcine oocyte maturation in vitro by improving the ROS in the oocytes ${ }^{41}$. Maternal-restraint stress increases oocyte aneuploidy by impairing metaphase I spindle assembly and reducing spindle assembly checkpoint proteins in mice ${ }^{42}$. To combat the negative effects of the excessive ROS and promote the maturation of oocytes and ovulation, antioxidants are frequently used in the in vitro culture system ${ }^{43,44}$. Melatonin is a naturally occurring potent free radical scavenger and a broad-spectrum antioxidant ${ }^{45,46}$. As a result, the use of melatonin to prevent oxidative stress in cell culture or animal studies has been extensively reported ${ }^{43,44}$. It was reported that under stressful heat conditions, melatonin application improved the feeding efficiency of Japanese quail and reduced their oxidative stress ${ }^{47}$. Moreover, melatonin could enhance immunity in chickens against disease ${ }^{14,48,49}$. As a result, these activities of melatonin may also help the hens preserve their egg-laying rate after their egg-laying peak age.

A few studies have investigated the effects of melatonin on the quality of eggs. Some researchers have observed that melatonin supplementation reallocated the calcium distribution between bone and eggshell in laying hens, suggesting that melatonin could strengthen the bone and weaken the eggshell ${ }^{50}$. Other reports have shown that melatonin application increased the eggshell weight and thickness ${ }^{51}$. These findings are consistent with our observations that melatonin implantation significantly reduced the sharpei egg rate.

\section{Conclusion}

Physiologically, once hens are older than 300 days of age, the hens have passed their egg-laying peak, and the egg-laying rate significantly declines with age ${ }^{20}$. Prolonging the egg-laying peak in chicken is task that remains to be accomplished. In the current study, we observed that implantation of the appropriate dose of melatonin $(10 \mathrm{mg} / \mathrm{hen})$ in laying hens up to 550 days of age significantly increased their egg-laying rate and egg quality. The results indicated that melatonin application may prolong the physiological egg-laying peak. Considering the low cost of melatonin, there may be an application for it in the poultry industry. The mechanistic studies revealed that melatonin implantation up-regulated the gene expression of $M T 2$ and down-regulated GnIHR in the granulosa cells of small white follicles. This finding indicated that melatonin may promote ovulation in hens through the GnIHR-LH-FSH pathway mediated by MT2 activation.

\section{Materials and Methods}

Chemicals. The melatonin implants were made by the Specialty Institute, Chinese Academy of Agricultural Sciences.

Animals. We selected 120 hens (Beijing Red No. 1) 300 days old, divided them into four groups, and treated them with either $0,5,10$ or $20 \mathrm{mg}$ of melatonin implants (C, $5 \mathrm{mg}, 10 \mathrm{mg}$, and $20 \mathrm{mg}$ groups, respectively). We randomly divided 240 hens ( 120 hens 360 days of age and 120 hens 470 days of age) into four groups at each age and treated them with $0,10,20$ and $30 \mathrm{mg}$ of melatonin (C,10 mg, $20 \mathrm{mg}$, and $30 \mathrm{mg}$ groups, respectively). We divided 60 hens 550 days old into 4 groups, and their treatment was the same as the hens in the 300 -day-old groups. Hens of different ages came from different hatches.

Melatonin implants were implanted under the neck skin of the birds. Birds were reared under photostimulatory conditions (16 L:8D) with a corn-soybean meal diet of $110 \mathrm{~g} / \mathrm{hen} /$ day. One cage $(40 \times 37 \times 35 \mathrm{~cm}$, length $\times$ width $\times$ height) contained 3 birds. The egg numbers and total egg weight of each group were monitored daily from at least 2 weeks before the treatment started until the termination of the study. All experimental procedures were approved by the animal care committee of the China Agricultural University, and all experiments were carried out in accordance with the relevant guidelines.

Melatonin assay using high-performance liquid chromatography (HPLC). To evaluate the melatonin level, blood samples ( $2 \mathrm{ml}$ for each hen) were drawn from the wing sinus of the chicken. The sample preparation and detection were performed as described by Zhao et al. ${ }^{52}$.

Analysis of progesterone (P4) and oestradiol-17 $\beta$ (E2) levels by radioimmunoassay. Blood samples $(2 \mathrm{ml}$ for each hen, $\mathrm{n}=20$ ) were drawn from the wing sinus of the chicken 3 months after melatonin implantation. Progesterone (P4) and oestradiol-17 (E2) were detected using radioimmunoassay using the method described by He et al. ${ }^{53}$. 


\begin{tabular}{|c|c|c|c|}
\hline Primer & GenBank ID & $\begin{array}{l}\text { Production } \\
\text { length bp }\end{array}$ & Sequence \\
\hline$\beta$-actin-F & \multirow{2}{*}{ L08165 } & \multirow{2}{*}{154} & GAGAAATTGTGCGTGACATCAAGG \\
\hline$\beta$-actin-R & & & CACCTGAACCTCTCATTGCCA \\
\hline LHR-F & \multirow{2}{*}{ u31987 } & \multirow{2}{*}{193} & CTCAGGCGGATACACAACGA \\
\hline LHR-R & & & TCAGAACGGCTTCCAGCAGG \\
\hline FSHR-F & \multirow{2}{*}{ NM_205079.1 } & \multirow{2}{*}{191} & TACCCGTCGTCCATAAGGTGC \\
\hline FSHR-R & & & GCTCATCCAGGCAGGTTCCATT \\
\hline $\mathrm{ER} \alpha-\mathrm{F}$ & \multirow{2}{*}{$\mathrm{NM}-205183.2$} & \multirow{2}{*}{157} & TATTGATGATCGGCTTAGTCTGGCG \\
\hline $\mathrm{ER} \alpha-\mathrm{R}$ & & & CGAGCAGCAGTAGCCAGTAGCA \\
\hline GnIHR-F & \multirow{2}{*}{ AB193127 } & \multirow{2}{*}{139} & CACTGATGCTGCTGACAGACTAC \\
\hline GnIHR-R & & & CTCATTGAAGTAGCCGTAGATGATGG \\
\hline MT1-F & \multirow{2}{*}{ NM_001097538.1 } & \multirow{2}{*}{127} & CAGGACTGCCCTTGTGCC \\
\hline MT1-R & & & CACACTTGGCACATCCTGC \\
\hline MT2-F & \multirow{2}{*}{ NM_205275.1 } & \multirow{2}{*}{99} & AACCGACCCGAACTGAACCA \\
\hline MT2-R & & & CAGCGGCAGTTCTTGCACTT \\
\hline SOD2-F & \multirow{2}{*}{ NM_204211.1 } & \multirow{2}{*}{157} & CGCAAGGCAGAAGCACACTC \\
\hline SOD2-R & & & CAGCGCCTCTTTGTATTTCTCC \\
\hline
\end{tabular}

Table 2. Primers used in this study.

Gene expression assay using reverse-transcriptional PCR (real-time PCR). The ovaries of hens 360 days of age $(\mathrm{n}=10)$ were collected after 3 months of melatonin implantation and were immediately frozen in liquid nitrogen for future use. The total RNA extraction, reverse transcription PCR and quantitative real-time PCR were performed as described previously ${ }^{54}$. A housekeeping gene ( $\beta$-actin) was used as the normalization control. The relative mRNA expression was calculated using the $2^{-\Delta \Delta \mathrm{ct}}$ method. Primer sequences for the real-time PCR are listed in Table 2.

Statistical analyses. The data were expressed as the means \pm SEM. The statistical significance was analysed using an ANOVA followed by the Dunnett's $\mathrm{t}$-test. The significance level was set at $\mathrm{p}<0.05$.

\section{References}

1. Dubey, S. \& Haldar, C. Environmental factors and annual harderian-pineal-gonadal interrelationship in Indian jungle bush quail, Perdicula asiatica. Gen. Comp. Endocr. 1, 17-22 (1997).

2. Gupta, B., Haldar-Misra, C., Ghosh, M. \& Thapliyal, J. P. Effect of melatonin on gonads, body weight, and luteinizing hormone (LH) dependent coloration of the Indian finch, Lal munia (Estrilda amandava). Gen. Comp. Endocr. 3, 451-456 (1987).

3. Rozenboim, I., Aharony, T. \& Yahav, S. The effect of melatonin administration on circulating plasma luteinizing hormone concentration in castrated White Leghorn roosters. Poultry Sci. 9, 1354-1359 (2002).

4. Ubuka, T., Bentley, G. E., Ukena, K., Wingfield, J. C. \& Tsutsui, K. Melatonin induces the expression of gonadotropin-inhibitory hormone in the avian brain. P. Natl Acad. Sci. USA. 8, 3052-3057 (2005).

5. Ganji, R., Nabiuni, M \& Faraji, R. Development of mouse preantral follicle after in vitro culture in a medium containing melatonin. Cell Journal (Yakhteh). 4, 546 (2015).

6. Valeri, C., Sbracia, G., Selman, H., Antonini, G. \& Pacchiarotti, A. Beneficial effects of melatonin on oocytes and embryo quality in aged IVF patients ed: OXFORD UNIV PRESS GREAT CLARENDON ST, OXFORD OX2 6DP, ENGLAND, 48-49 (2015).

7. Do, L. et al. Melatonin supplementation during in vitro maturation and development supports the development of porcine embryos. Reprod. Domest. Anim. 6, 1054-1058 (2015).

8. Zhao, X. et al. Melatonin enhances the in vitro maturation and developmental potential of bovine oocytes denuded of the cumulus oophorus. Zygote. 4, 525-536 (2015).

9. Casao, A. et al. Melatonin secretion in sheep cumulus cells and its possible effect on DNA damage during in vitro maturation. ed: Asociación Interprofesional para el Desarrollo Agrario, 368-370 (2013).

10. Clark, W. D. \& Classen, H. L. The effects of continuously or diurnally fed melatonin on broiler performance and health. Poultry Sci. 11, 1900-1904 (1995).

11. Phetteplace, H. W. \& Nockels, C. F. Melatonin increases cockerel growth ed: FEDERATION AMER SOC EXP BIOL 9650 ROCKVILLE PIKE, BETHESDA, MD 20814-3998 USA, 761 (1985).

12. Poon, A. et al. Evidence for a direct action of melatonin on the immune system. Neurosignals. 2, 107-117 (1994).

13. Moore, C. B. \& Siopes, T. D. Effects of lighting conditions and melatonin supplementation on the cellular and humoral immune responses in Japanese quail Coturnix coturnix japonica. Gen. Comp. Endocr. 1, 95-104 (2000).

14. Brennan, C. P., Hendricks, G. L., El-Sheikh, T. M. \& Mashaly, M. M. Melatonin and the enhancement of immune responses in immature male chickens. Poultry Sci. 3, 371-375 (2002).

15. Kliger, C. A. et al. Effects of photoperiod and melatonin on lymphocyte activities in male broiler chickens. Poultry Sci. 1, 18-25 (2000).

16. Moore, C. B. \& Siopes, T. D. Effect of melatonin supplementation on the ontogeny of immunity in the Large White turkey poult. Poultry Sci. 12, 1898-1903 (2002).

17. Drazen, D. L. \& Nelson, R. J. Melatonin receptor subtype MT2 (Mel 1b) and not mt1 (Mel 1a) is associated with melatonin-induced enhancement of cell-mediated and humoral immunity. Neuroendocrinology. 3, 178-184 (2001).

18. Yaoxing, C. \& Zixu, W. Effect and mechanism of monochromatic light on the peak period of Laying Hens. Journal of China Agricultural University (2007).

19. Ailian, G. et al. Comparison of layer's health and welfare under different cage conditions. Journal-China Agricultural University 5, 67 (2007). 
20. Lukanov, H., Petrov, P., Genchev, A., Halil, E. \& Ismail, N. Productive performance of easter egger crosses of araucana and schijndelaar roosters with white leghorn hens. Trakia Journal of Sciences. 1, 73 (2016).

21. Maddineni, S. et al. Gonadotrophin-inhibitory hormone receptor expression in the chicken pituitary gland: Potential influence of sexual maturation and ovarian steroids. J. Neuroendocrinol. 9, 1078-1088 (2008).

22. McGuire, N. L., Kangas, K. \& Bentley, G. E. Effects of melatonin on peripheral reproductive function: Regulation of testicular GnIH and testosterone. Endocrinology. 9, 3461-3470 (2011).

23. Maganhin, C. C. et al. Effects of melatonin on ovarian follicles. Eur. J. Obstet. Gyn. R. B. 2, 178-184 (2013).

24. Do, L. et al. Melatonin supplementation during in vitro maturation and development supports the development of porcine embryos. Reprod. Domest. Anim. 6, 1054-1058 (2015).

25. Shi, J. M. et al. Melatonin exists in porcine follicular fluid and improves in vitro maturation and parthenogenetic development of porcine oocytes. J. Pineal Res. 4, 318-323 (2009).

26. Wei, D. et al. Supplementation with low concentrations of melatonin improves nuclear maturation of human oocytes in vitro. J. Assist. Reprod. Gen. 7, 933-938 (2013).

27. He, Y. M. et al. Melatonin modulates the functions of porcine granulosa cells via its membrane receptor MT2 in vitro. Anim. Reprod. Sci. 17, 164-172 (2016).

28. Moniruzzaman, M., Hasan, K. N. \& Maitra, S. K. Melatonin actions on ovaprim (synthetic GnRH and domperidone)-induced oocyte maturation in carp. Reproduction. 4, 285-296 (2016).

29. Maitra, S. K., Chattoraj, A., Mukherjee, L. \& Moniruzzaman, M. Melatonin: A potent candidate in the regulation of fish oocyte growth and maturation. Gen. Comp. Endocr. 215-222 (2013).

30. Sundaresan, N. R. et al. Expression analysis of melatonin receptor subtypes in the ovary of domestic chicken. Vet. Res. Commun. 1, 49-56 (2009).

31. Li, D. Y. et al. Expression patterns of melatonin receptors in chicken ovarian follicles affected by monochromatic light. Genet. Mol. Res. 3, 10072-10080 (2015).

32. Maddineni, S. et al. Gonadotropin inhibitory hormone $(\mathrm{GnIH})$ receptor gene is expressed in the chicken ovary: Potential role of GnIH in follicular maturation. Reproduction. 2, 267-274 (2008).

33. Lebedeva, I. Y., Lebedev, V. A., Grossmann, R. \& Parvizi, N. Age-dependent role of steroids in the regulation of growth of the hen follicular wall. Reprod. Biol. Endocrin. 1, 1 (2010).

34. Wistedt, A., Ridderstråle, Y., Wall, H. \& Holm, L. Exogenous estradiol improves shell strength in laying hens at the end of the laying period. Acta Vet. Scand. 1, 1 (2014).

35. Mattsson, A., Mura, E., Brunström, B., Panzica, G. \& Halldin, K. Selective activation of estrogen receptor alpha in Japanese quail embryos affects reproductive organ differentiation but not the male sexual behavior or the parvocellular vasotocin system. Gen. Comp. Endocr. 2, 150-157 (2008).

36. Hansen, K. K., Beck, M. M., Scheideler, S. E. \& Blankenship, E. E. Exogenous estrogen boosts circulating estradiol concentrations and calcium uptake by duodenal tissue in heat-stressed hens. Poultry Sci. 6, 895-900 (2004).

37. Li, Q. et al. Glucose metabolism in mouse cumulus cells prevents oocyte aging by maintaining both energy supply and the intracellular redox potential. Biol. Reprod. 6, 1111-1118 (2011).

38. Yoon, J. D. et al. Effects of coculture with cumulus-derived somatic cells on in vitro maturation of porcine oocytes. Theriogenology. 2, 294-305 (2015).

39. He, C. J. et al. Melatonin and its receptor MT1 are involved in the downstream reaction to luteinizing hormone and participate in the regulation of luteinization in different species. J. Pineal Res. 3, 279-290 (2016).

40. Babayev, E. et al. Reproductive aging is associated with changes in oocyte mitochondrial dynamics, function, and mtDNA quantity. Maturitas. 14,121-130 (2016).

41. Li, Y. et al. Melatonin protects porcine oocyte in vitro maturation from heat stress. J. Pineal Res. 3, 365-375 (2015).

42. Zhou, P. et al. Maternal-restraint stress increases oocyte aneuploidy by impairing metaphase I spindle assembly and reducing spindle assembly checkpoint proteins in mice. Biol. Reprod. 3, 83 (2012).

43. Bormann, C. L., Ongeri, E. M. \& Krisher, R. L. The effect of vitamins during maturation of caprine oocytes on subsequent developmental potential in vitro. Theriogenology. 5, 1373-1380 (2003).

44. Wang, F. et al. Beneficial effect of resveratrol on bovine oocyte maturation and subsequent embryonic development after in vitro fertilization. Fertil. Steril. 2, 577-586 (2014).

45. Manchester, L. C. et al. Melatonin: An ancient molecule that makes oxygen metabolically tolerable. J. Pineal Res. 4, 403-419 (2015).

46. Reiter, R. J., Tan, D. X. \& Maldonado, M. D. Melatonin as an antioxidant: Physiology versus pharmacology. J. Pineal Res. 2, 215-216 (2005).

47. Sahin, K., Onderci, M., Gursu, M. F., Kucuk, S. M. \& Sahin, G. L. Effect of melatonin supplementation on biomarkers of oxidative stress and serum vitamin and mineral concentrations in heat-stressed Japanese quail. The Journal of Applied Poultry Research. 2, 342-348 (2004)

48. Markowska, M., Mrozkowiak, A. \& Skwarlo-Sonta, K. Influence of melatonin on chicken lymphocytes in vitro: Involvement of membrane receptors. Neuro endocrinology letters. 6, 67-72 (2002).

49. Liu, S. et al. Effect of melatonin on changes of lymphocytes and their subtypes of chickens, ducks and quails in different light [J]. Veterinary Science in China. 15 (2006).

50. Taylor, A. C., Horvat-Gordon, M., Moore, A. \& Bartell, P. A. The effects of melatonin on the physical properties of bones and egg shells in the laying hen. PloS one. 2, e55663 (2013).

51. Jain, A. et al. Studies on production performance of layers supplemented with dietary melatonin. Indian Journal of Poultry Science. 3, 345-347 (2012).

52. Zhao, Y. et al. Melatonin and its potential biological functions in the fruits of sweet cherry. J. Pineal Res. 1, 79-88 (2013).

53. He, C. et al. Melatonin-related genes expressed in the mouse uterus during early gestation promote embryo implantation. J. Pineal Res. 3, 300-309 (2015).

54. Li, Y. et al. Melatonin protects porcine oocyte in vitro maturation from heat stress. J. Pineal Res. 3, 365-375 (2015).

\section{Acknowledgements}

This research was supported by the National Natural Science Foundation of China (31372306) and the poultry industry technology system innovation team of Beijing.

\section{Author Contributions}

Yaxiong Jia, Kuanfeng Zhu and Minghui Yang designed and participated in the entire experiment and wrote the manuscript. Minghui Yang and Liang Wang participated in the data collection and analyses. Yukun Song assisted with the sample collection. Jing Wang performed the melatonin analysis. Wenxiang Qin, Zhiyuan Xu and Yu Chen all participated in the different stages of the study. All experiments were directed by Guoshi Liu. All authors reviewed the manuscript. 


\section{Additional Information}

Competing financial interests: The authors declare no competing financial interests.

How to cite this article: Jia, Y. et al. Melatonin implantation improved the egg-laying rate and quality in hens past their peak egg-laying age. Sci. Rep. 6, 39799; doi: 10.1038/srep39799 (2016).

Publisher's note: Springer Nature remains neutral with regard to jurisdictional claims in published maps and institutional affiliations.

(c) (i) This work is licensed under a Creative Commons Attribution 4.0 International License. The images or other third party material in this article are included in the article's Creative Commons license, unless indicated otherwise in the credit line; if the material is not included under the Creative Commons license, users will need to obtain permission from the license holder to reproduce the material. To view a copy of this license, visit http://creativecommons.org/licenses/by/4.0/

(C) The Author(s) 2016 